\title{
The three-dimensional prey field of the northern krill, Meganyctiphanes norvegica, and the escape responses of their copepod prey
}

\author{
Mari B. Abrahamsen - Howard I. Browman • \\ David M. Fields • Anne Berit Skiftesvik
}

Received: 30 May 2009/ Accepted: 2 February 2010/Published online: 24 February 2010

(C) The Author(s) 2010. This article is published with open access at Springerlink.com

\begin{abstract}
In the north Atlantic, Meganyctiphanes norvegica feeds predominantly on copepods, including Calanus spp. To quantify its perceptual field for prey, and the sensory systems underlying prey detection, the responses of tethered krill to free-swimming Calanus spp. were observed in 3D using silhouette video imaging. An attack-which occurred despite the krill's being tetheredwas characterized by a pronounced movement of the krill's antennae towards the target, followed by a propulsion and opening of the feeding basket. Frequency distributions of prey detection distances were significantly different in the light vs. the dark, with median values of $26.5 \mathrm{~mm}$ and $19.5 \mathrm{~mm}$, respectively. There were no significant differences in the angles at which prey were detected by krill (relative to the predator's longitudinal body axis) in the light vs. the dark. Prey detections were symmetrically distributed on either side of the predator, in
\end{abstract}

Communicated by X. Irigoien.

Electronic supplementary material The online version of this article (doi:10.1007/s00227-010-1405-9) contains supplementary material, which is available to authorized users.

M. B. Abrahamsen

Institute of Marine Research, Post Box 1870,

Nordnes, Bergen 5817, Norway

H. I. Browman $(\bowtie) \cdot$ D. M. Fields · A. B. Skiftesvik Institute of Marine Research, Austevoll Research Station, 5392 Storebø, Norway

e-mail: howard.browman@imr.no

D. M. Fields

Bigelow Laboratory for Ocean Sciences,

West Boothbay Harbor, Maine, ME 04575-0475, USA both light and dark. However, significant asymmetry was found in the dorsal-ventral direction with $80 \%$ of the prey detections located below the midline of the krill's body axis and, given the placement and orientation of the compound eyes, presumably outside its visual field of view. This indicates that, at least under these conditions, vision was not the main sensory modality involved in the detection of active prey by $M$. norvegica. However, under some circumstances, vision may provide supplemental information. Avoidance responses of copepod prey were nearly twice the velocity of their nominal background swimming speed $\left(153 \pm 48\right.$ and $85 \pm 75 \mathrm{~mm} \mathrm{~s}^{-1}$, respectively), on average taking them $43 \pm 16 \mathrm{~mm}$ away from the predator. This is far beyond the krill's perceptual range, suggesting that the escape reaction provides an effective deterrent to predation (although perhaps less so for free-swimming krill). This information can be used to parameterize models that assess the role of krill as predators in marine ecosystems.

\section{Introduction}

There is a general lack of detailed empirical data to support the parameterization of ecosystem models (or compartments thereof) concerned with predicting predator-prey interactions in the plankton (e.g. Fiksen et al. 2005; Mori and Butterworth 2006; North et al. 2009). This is particularly true for the euphausiid Meganyctiphanes norvegica.

Meganyctiphanes norvegica is a keystone organism in high-latitude marine ecosystems, acting as a bridge between primary and secondary production and larger predators (e.g. Båmstedt and Karlson 1998; Lass et al. 2001; Mori and Butterworth 2006). In the north Atlantic, $M$. norvegica inhabits both coastal and offshore waters 
(Båmstedt and Karlson 1998; Kaartvedt et al. 2002) and typically aggregates in large swarms and schools that undertake pronounced vertical migrations (Onsrud and Kaartvedt 1998; Kaartvedt et al. 2005). M. norvegica is preyed upon by commercially important fishes (Sameoto et al. 1994; Onsrud et al. 2004, seabirds (Montevecchi et al. 1992; Stevick et al. 2008) and marine mammals (Brodie et al. 1978). While opportunistically herbivorous and/or omnivorous, $M$. norvegica prey mainly upon copepodstheir diet is often dominated by Calanus and Pseudocalanus spp. (e.g. McClatchie 1985; Båmstedt and Karlson 1998; Virtue et al. 2000; Kaartvedt et al. 2002). Little is known about the predatory behaviour of this species, the sensory basis for prey detection and location, and the dimensions and geometry of the perceptual field for prey (although see Torgersen 2001). Empirical observations such as this are essential for the accurate parameterization of ecosystem models that include northern krill as a predator.

The aims of this study were to (1) describe the threedimensional (3-D) perceptual field of Meganyctiphanes norvegica feeding on Calanus spp., (2) investigate the sensory systems involved in prey detection by $M$. norvegica and (3) characterize the avoidance response of Calanus spp.

\section{Materials and methods}

Specimen collection

Meganyctiphanes norvegica were collected at night from net trawls in Raunefjorden, Norway $\left(60^{\circ} 19^{\prime} \mathrm{N}, 5^{\circ} 08^{\prime} \mathrm{E}\right)$ using an Isaac Kidd mid-water trawl. The trawls were towed at 2 knots by the RV Hans Brattstrøm for $15 \mathrm{~min}$ at $20 \mathrm{~m}$ during the night in February 2004. To minimize damage to the krill, a 50-1 plastic sac was used as a closed cod end. Krill were immediately transferred into 230-ml polypropylene jars (one individual per jar) onboard the ship and lowered into a bucket of circulating water. Krill were transported to the Institute of Marine Research, Austevoll Research Station, within 4-6 h after collection and were maintained in flowing filtered seawater at $6^{\circ} \mathrm{C}$. Krill were used in experiments within $48 \mathrm{~h}$ of collection and were never exposed to light, except during the experiment. All experiments were conducted during the day between 8:00 and 18:00. Only krill in excellent physical condition were used in the experiments.

Behavioural observations

Behavioural observations were conducted in glass aquaria $(20 \times 20 \times 20 \mathrm{~cm})$ surrounded by black contact paper (except for $15 \mathrm{~cm}$ openings that allowed viewing from the sides) (see Fig. 1 in Browman et al. 2003). Silhouette images were produced using a low-intensity, far red emitting LED light source that is outside Meganyctiphanes norvegica's spectral sensitivity (Denys and Brown 1982). The behaviour of $M$. norvegica and its Calanus spp. prey were recorded from 2 orthogonal angles using a 3-D silhouette imaging system described in detail elsewhere (Browman et al. 2003). Free-swimming krill stay at the bottom of the tank or in the corners, making it difficult to obtain observations of their feeding behaviour. To keep animals in the field of view at all times, krill were tethered to a wire-attached dorsally to the carapace using cyanoacrylate superglueand placed in the centre of the aquarium. Similar methods have been employed in analogous studies with other krill species (e.g. Yen et al. 2003; Patria and Wiese 2004; Catton et al. 2007). All experiments were conducted at $6^{\circ} \mathrm{C}$ in a climate- and light-controlled room.

Prey for the krill was collected by towing a WP2 net $(180 \mu \mathrm{m})$ vertically from $15 \mathrm{~m}$ depth to the surface, off of the pier at the Austevoll Research Station. The content of the tows were collected on a $1,000 \mu \mathrm{m}$ mesh to eliminate small-bodied species and life stages. After each experiment, the content of the aquarium was preserved for later determination of the krill size and the species composition of copepod prey.

Thirty minutes prior to an experiment, the observation aquarium was filled with filtered seawater (90 $\mu \mathrm{m}$ sieve) from the same source as that from which the krill were maintained. One tethered krill was placed in the centre of the field of view. Freshly collected zooplankton (80-153 individuals; counted and taxonomical determined after the experiment) were added, and the interactions recorded onto SVHS tape for approximately $1 \mathrm{~h}$. A total of $11 \mathrm{krill}-6$ individuals filmed in the light and 5 individuals filmed in the dark-were analysed. All krill in each light treatment were considered (statistically) as independent replicates. All analysed prey behaviours (detection and/or attack or avoidance events) were considered independent samples within each light treatment (see Table 1 for details on sample sizes).

Feeding experiments were conducted under two light conditions (On:Off). Light was generated using a downwelling collimated beam of broadband light (340-800 nm) produced by a $1-\mathrm{kW}$ Xenon arc lamp at an integrated irradiance of $3.99 \mathrm{e}^{-5} \mathrm{~W} \mathrm{~cm}{ }^{-2}$. This intensity falls within the range of what this species encounters during its nightly ascent to the surface waters at this geographic region (Onsrud and Kaartvedt 1998). The spectral composition of the light was similar to that produced by the halogen lamp used by Torgersen (2001). 
Table 1 Summary statistics (mean \pm standard deviation) of variables measured on tethered Meganyctiphanes norvegica in the light and dark in the presence of copepod prey (mainly C5-adult Calanus spp.)

\begin{tabular}{|c|c|c|c|c|c|}
\hline & Light & Dark & DF & $p$-value & Test \\
\hline Krill size $(\mathrm{mm})$ & $28.5 \pm 0.8$ & $27.2 \pm 4.9$ & 11 & ns & $t$-test \\
\hline $\begin{array}{l}\text { Distance at which krill detected prey } \\
\text { (all combined) }(\mathrm{mm})\end{array}$ & $\begin{array}{l}26.65 \pm 10.42 \\
26.5(\text { median })\end{array}$ & $\begin{array}{l}22.96 \pm 12.78 \\
19.5(\text { median })\end{array}$ & 102 & 0.017 & M-W \\
\hline Distance at which krill detected prey (lateral) $(\mathrm{mm})$ & $15.85 \pm 9.79$ & $14.42 \pm 9.76$ & 100 & ns & $t$-test \\
\hline $\begin{array}{l}\text { Distance at which krill detected prey } \\
\text { (above the body axis) (mm) }\end{array}$ & $14.51 \pm 8.32$ & $17.65 \pm 7.71$ & 18 & ns & $t$-test \\
\hline $\begin{array}{l}\text { Distance at which krill detected prey } \\
\text { (below the body axis) (mm) }\end{array}$ & $20.91 \pm 7.90$ & $17.47 \pm 10.20$ & 80 & 0.049 & $t$-test \\
\hline Copepod size (mm) & $3.1 \pm 0.3$ & $3.2 \pm 0.3$ & 100 & $\mathrm{~ns}$ & $t$-test \\
\hline Distance at which copepods reacted to krill (mm) & $22.46 \pm 8.76$ & $18.13 \pm 8.96$ & 101 & 0.013 & $t$-test \\
\hline Nominal copepod swim speed $\left(\mathrm{mm} \mathrm{s}^{-1}\right)$ & $83.78 \pm 68.42$ & $86.84 \pm 85$ & 104 & ns & $t$-test \\
\hline Copepod escape speed $\left(\mathrm{mm} \mathrm{s}^{-1}\right)$ & $156.80 \pm 43.54$ & $147.79 \pm 53.40$ & 77 & $\mathrm{~ns}$ & $t$-test \\
\hline Displacement of copepods after escape (mm) & $35.93 \pm 19.41$ & $35.05 \pm 17.42$ & 77 & $\mathrm{~ns}$ & $t$-test \\
\hline $\begin{array}{l}\text { Distance between predator and prey } \\
\text { after escape reaction }(\mathrm{mm})\end{array}$ & $44.85 \pm 16.01$ & $41.21 \pm 15.29$ & 77 & $\mathrm{~ns}$ & $t$-test \\
\hline
\end{tabular}

Statistical tests are considered statistically discernable at $p<0.05$

Behavioural and statistical analyses

Videotaped observations of krill and their prey were analysed frame-by-frame using motion tracking software developed for taking 3-D measurements from video images obtained from the silhouette imaging system (TRAKFISH, MANTRAK and MEASURE, JASCO Scientific, Victoria, B.C., Canada; see Browman et al. (2003) for details). Measurements were made using MEASURE software, which superimposes a virtual airplane (which has distinct dorso-ventral, lateral and frontrear axes) onto the krill's body. Once this was done for both orthogonal views, the prey's location just prior to their escape (distances and angles relative to the krill's longitudinal body axis and symmetry) were recorded. The midpoint between the eyes of the krill and the middle of the copepod's body were used as reference points for measuring the distances between predator and prey. The MEASURE software was also used to measure the body length of copepods.

A krill attack - which occurred despite being tetheredwas defined as a rapid $(<0.4 \mathrm{~s})$ response directed towards a swimming copepod. An attack involved rapid movement of the pleopods and opening of the feeding basket. Although we periodically observed krill adjusting their maxillipeds in the absence of prey, we never saw the animal fully extend the maxillipeds except in response to an approaching copepod. The vertical and lateral angles between the krill and the copepod (at the instant that the attach was initiated) were defined relative to the krill's longitudinal body axis, with the krill's anterior being $0^{\circ}$ and its posterior $180^{\circ}$. Positive vertical angles correspond to dorsal locations and negative angles to ventral locations.

To establish the krill's perceptual field for copepod prey, the distances and angles between the krill and detected copepods were measured before and after an attack. Detection distances was determined a posteriori, as the distance between the krill (from the position of the compound eyes) and the prey at the instant at which the krill first exhibited a reaction to the prey's movement. The krill's longitudinal body axis was used as the reference line against which angles were measured. Swimming velocities of the prey were calculated from the measured displacement over sequential video frames. Looping copepod trajectories were analysed frame-by-frame to minimize the underestimation of velocities associated with such nonlinear tracks.

Two sample $t$-tests (S-plus, Lucent Technologies, Inc.) were used to compare central tendencies. In cases where the data were not normally distributed, a Mann-Whitney U test was used. A significance level of $p=0.05$ was applied for all statistical tests.

\section{Results}

There was no difference in the size of the krill specimens used in the two treatments (Table 1). The zooplankton used as prey was dominated by Calanus spp. (C. finmarchicus and C. helgolandicus $\mathrm{C} 5$ and adult contributing $93.8 \pm 2.8 \%$ of 


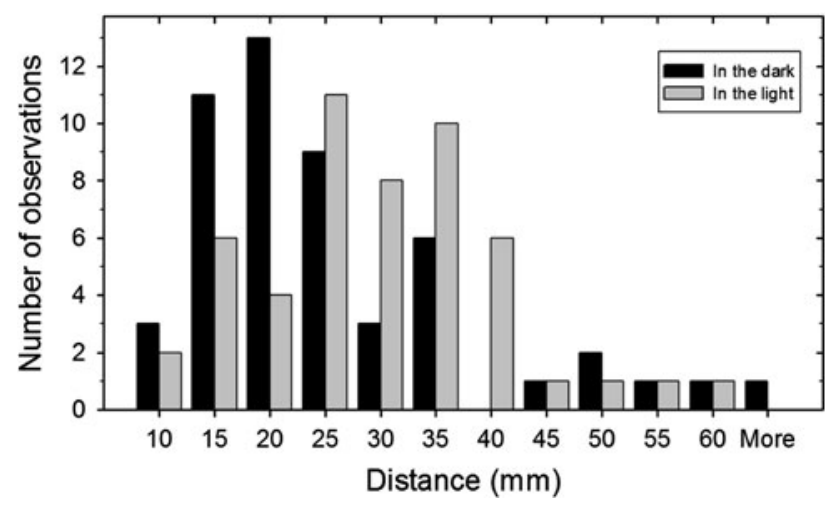

Fig. 1 Distance of tethered Meganyctiphanes norvegica from its copepod prey (Calanus spp.) when it initiated an attack response in the light and dark

the total by number) with a small number of younger stages of Calanus spp. (C4-C3). Relatively small numbers of Metridia longa, Acartia spp, Sagitta spp, Aglanta digitalis and Isopoda sp. were also present.

Predatory behaviour of krill and the perceptual field for prey

There was no difference in body length between the copepods used in the light vs. dark treatments (Table 1). Krill detected the prey significantly further in the dark vs. the light (Table 1; Fig. 1) with median values 19.5 vs. $26.5 \mathrm{~mm}$.

Prey attack distances were laterally symmetrical as were the number of attacks on either side of the krill (Fig. 2a). In contrast, there was clear asymmetry in the number of attacks above and below the animal (Fig. 2b). The per cent of attacks in the upper hemisphere in the dark was less than that in the lower hemisphere (18 and 82\%, respectively). In the light, the per cent of attacks in the upper hemisphere increased to $23 \%$ with $77 \%$ of all attacks occurring below the midline.

Escape responses of copepods

There was no statistically significant difference in copepod swimming speed (nominal displacement velocity during "hops") between the light and dark treatments (Table 1). The hop speed of copepods, measured prior to attacks, ranged from 3 to $360 \mathrm{~mm} \mathrm{~s}^{-1}$, with $37 \%$ of the animals travelling $25 \mathrm{~mm} \mathrm{~s}^{-1}$ or less (Fig. 3).

While some of the copepods were attacked by the krill and then escaped, most copepods initiated an escape reaction prior to being attacked. The escape reaction appeared to have been triggered by the beating of the krill's pleopods and feeding appendages. The escape response consisted of a series of power strokes that moved the copepod away from the krill. The speed of the escapes
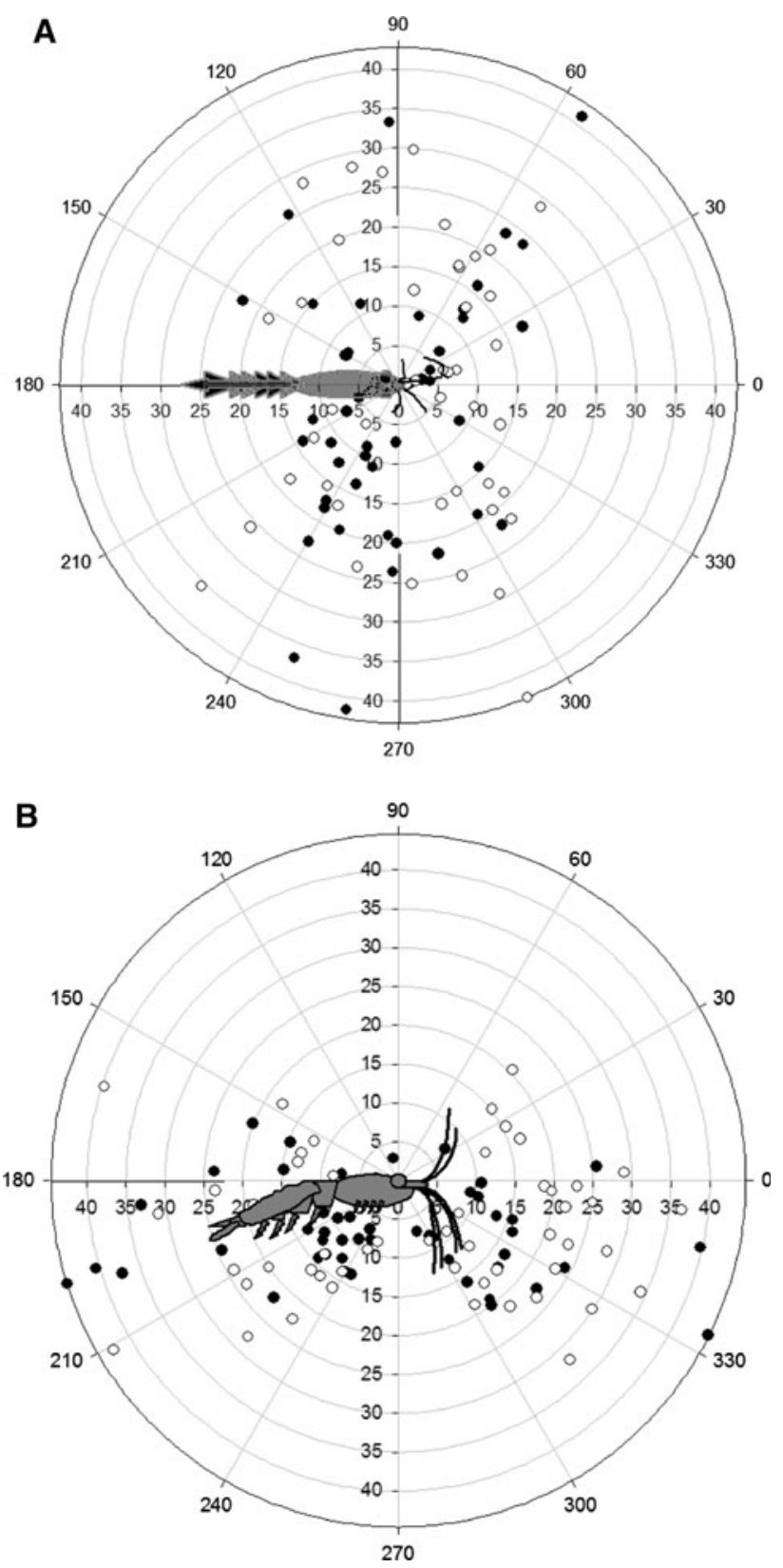

Fig. 2 Distance in the vertical plane (a) and horizontal plane (b) between the eyes of Meganyctiphanes norvegica and detected copepod prey (Calanus spp.). Open circles represent the location of the attacks in light, closed circle are the locations of attacks in dark

were significantly different than the nominal swimming speed of the copepods (Fig. 3; Table 1). Copepods escaped at a greater distance from the krill in the light than in the dark (Table 1). Once initiated, however, the kinematics of the escape reaction were unaffected by the light level: that is, there was no statistically discernible difference between light and dark treatments in the mean copepod escape velocity, in the total distance travelled by copepods during escape reactions or in the distance between the krill and the copepod after the escape reaction (Table 1). 


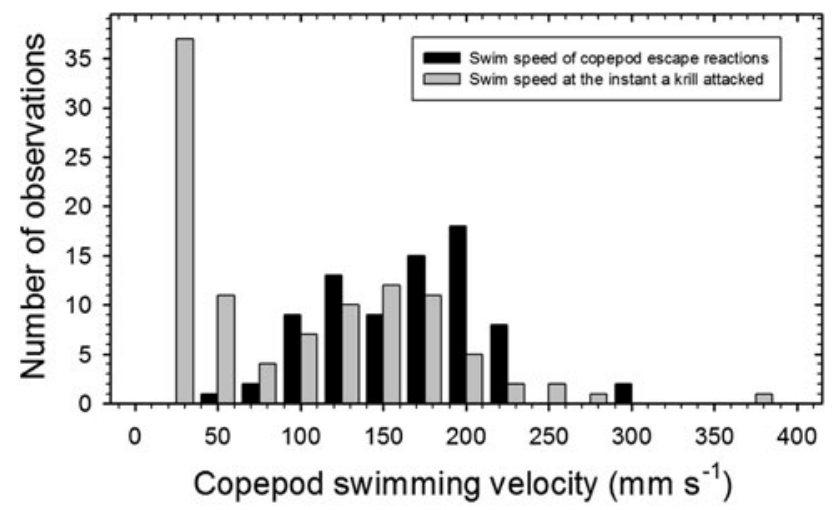

Fig. 3 Calanus spp. swimming speed prior to attack by Meganyctiphanes norvegica and during escape reactions in response to perceiving the flow fields of $M$. norvegica

\section{Discussion}

We observed attack responses by Meganyctiphanes norvegica to older life stages of Calanus spp., the dominant component of their natural diets (Båmstedt and Karlson 1998), to characterize the size and geometry of their perceptual field and to identify the primary sensors used in prey detection. $M$. norvegica attack targets with a rapid response towards the location of their prey. This oriented behaviour requires that $M$. norvegica not only distinguish the stimuli associated with potential prey from a potential predator or conspecific, but they must also localize these signals in 3D space. Direct physical contact is not necessary for prey detection, although it may be important for prey selection at the time of capture and ingestion. Attack responses are initiated well before potential prey items reach the krill's feeding appendages. In the rare cases where we observed contact between $M$. norvegica and a rapidly swimming copepod, $M$. norvegica exhibited a rapid escape reaction (despite being tethered).

Meganyctiphanes norvegica encounter potential prey through active swimming and/or entrainment in its powerful directed flow field. Using their pleopods (to create the flow) and urosome (to steer the flow), water is entrained from below and anterior of the animal and directed away in a narrow, asymmetric jet-like feature posterior and below the animal (Patria and Wiese 2004). Entrainment speeds for $M$. norvegica are on the order of $0.1-1 \mathrm{~cm} \mathrm{~s}^{-1}$ while the jet flow can reach a maximum speed of nearly $5.0 \mathrm{~cm} \mathrm{~s}^{-1}$. Similar fluid velocities were reported for the comparably sized Euphausia pacifica (Yen et al. 2003). Once M. norvegica and their potential prey are within several body lengths of each other, their relative ability to detect each other, attack or escape, determines who prevails in the predation cycle. The sensory systems potentially underlying the detection and localization of prey by $M$. norvegica include vision, mechanical and/or chemical detection. These different sensory systems may operate within a nested temporal and spatial scaling with, for example, vision used for detection of predators and/or swarms of prey, followed by mechanoreception as distances and/or light levels decrease. The role of chemoreception remains unexplored.

Geometry of the perceptual field and volume of water searched

The maximum detection volume of Meganyctiphanes norvegica is determined by the sensory system employed, environmental parameters (e.g. light intensity, turbulence (Fields unpl)) and the size and mobility Brewer and Coughlin 1995 of their potential prey. The attack volume for $M$. norvegica feeding on copepodid $\mathrm{CV}$ and adult Calanus spp. suggests a strong bias for attacking prey located ventrally as opposed to dorsally relative to the predator's longitudinal body axis (Fig. 2; Table 2). In the dark, approximately $20 \%$ of the prey detections were above the animal whereas in the light this increased to $25 \%$. No lateral bias was observed in the probability or distance at which prey were detected. Based upon the distribution of attacks, the geometry of the attack volume is well described by a hemisphere centred on the head of the animal with the flat side parallel to the medial plane of the krill (Fig. 2; Table 2). Using maximum detection distances observed in both the dark and the light $(5 \mathrm{~cm})$, the potential volume of the perceptual field is estimated at $\sim 260 \mathrm{ml}$. The same estimate based on mean attack distances $(23 \mathrm{~mm}$ in the dark vs. $27 \mathrm{~mm}$ in the light) yields an encounter volume of $\sim 25 \mathrm{ml}$ in the dark and $41 \mathrm{ml}$ in the light. The area of the encounter volume in conjunction with the flux of fluid through it can be used to estimate the potential volume sampled per hour by individual krill. While these values may overestimate the actual volume of water that an animal can scan for prey, they nonetheless provide a hypothetical maximum against which actual values can be compared. Although detailed flow measurements for $M$. norvegica are unavailable, the flow field measurements for a similarly sized Euphausia pacifica (Yen et al. 2003) can be used to estimate the flux of fluid through $M$. norvegica's encounter volume. The core of the water jet is approximately $1 \mathrm{~cm}$ in diameter $\left(0.79 \mathrm{~cm}^{2}\right)$, at a distance of $1 \mathrm{~cm}$ from the head of the animal, with an average velocity through this area of $\sim 2.5 \mathrm{~cm} \mathrm{~s}^{-1}$. Flow field data suggest that over $90 \%$ of the entrained fluid comes from slightly below the animal giving a volume scanned of $\left(1 \mathrm{~cm}^{2} \times 2.5 \mathrm{~cm} \mathrm{~s}^{-1} \times 0.9\right)$ of $2.5 \mathrm{ml} \mathrm{s}^{-1}$ or $8.11 \mathrm{~h}^{-1}$.

Torgersen (2001) reports clearance rates of 0.4 copepods krill $^{-1} \mathrm{~h}^{-1}$ in the light and 0.1 copepods krill ${ }^{-1} \mathrm{~h}^{-1}$ in the dark at concentrations of 1.6 copepods $1^{-1}$. This is equivalent to 0.21 and 0.11 of volume cleared krill ${ }^{-1} \mathrm{~h}^{-1}$ in the 
Table 2 Dimensions of different quadrants of the perceptual field of Meganyctiphanes norvegica feeding on Calanus finmarchicus and $C$. helgolandicus (mainly $\mathrm{C} 5$-adult). $\mathrm{n} / \mathrm{a}=$ insufficient data to make a calculation

\begin{tabular}{lcccc}
\hline & Angle from eye & & \\
\cline { 2 - 5 } & $0-45$ & $46-90$ & $91-135$ & $136-180$ \\
\hline Lateral distance at which krill detected prey $(\mathrm{mm})$ & $6.88 \pm 4.90$ & $20.86 \pm 7.68$ & $20.48 \pm 9.19$ & $8.38 \pm 6.24$ \\
$\begin{array}{l}\text { Vertical distance at which krill detected prey } \\
\quad(\text { below the body axis) }(\mathrm{mm})\end{array}$ & $21.70 \pm 8.93$ & $15.16 \pm 6.71$ & $13.66 \pm 5.25$ & $22.76 \pm 10.91$ \\
$\begin{array}{l}\text { Vertical distance at which krill detected prey } \\
\quad(\text { above the body axis) }(\mathrm{mm})\end{array}$ & $17.64 \pm 6.65$ & $\mathrm{n} / \mathrm{a}$ & $2.89 \pm \mathrm{n} / \mathrm{a}$ & $16.72 \pm 8.56$ \\
\hline
\end{tabular}

light and dark, respectively. This is lower than the volume sampled as estimated from flow rates through the encounter volume (i.e. $8.1 \mathrm{l} \mathrm{h}^{-1}$ ) indicating that there is a large discrepancy between the encounter volume (and encounter probability) and the capture success. These calculations provide indirect evidence that the copepod escape reaction is an effective means of predator avoidance (see below).

Sensory basis of prey detection by Meganyctiphanes norvegica

\section{Vision}

Vision serves as the primary sensory modality used to detect prey for only a small number of aquatic crustaceans. The cyclopoid copepod (Cyracaeus anglicus) (Gophen and Harris 1981) and the freshwater mysid (Mysis relicta: Ramcharan and Sprules 1986) are two well-studied examples that have eyes that are morphologically similar to those of Meganyctiphanes norvegica (Hallberg and Nilsson 1983), suggesting that $M$. norvegica may be a visual predator. The predation rate by $M$. norvegica feeding on hibernating and on active copepod prey was higher in the light than in the dark (Torgersen 2001; Kaartvedt et al. 2002). At the relatively low light intensities used in the present study, there was a small but significant increase $(\sim 16 \%)$ in the detection of highly active prey such as Calanus spp. in the light vs. the dark. As discussed below, this small increase in average detection distance nearly doubles the instantaneous sampling volume making vision an important aspect of $M$. norvegica's feeding ecology. Based upon attack behaviour, the greatest increase in detection distance occurred in front and slightly above the predator (Fig. 2). In this study, as in natural conditions, it is likely that $M$. norvegica benefit from down-welling light to maximize the contrast of potential prey. These results support previous observations of increased ingestion rates by $M$. norvegica in light vs. dark conditions (Torgersen 2001). However, as mentioned above, it was unclear in these earlier studies whether the increased ingestion rates were due to an increase in prey detection (visually based) by $M$. norvegica or to decreased escape reactions of their prey. In this study, we found that light increased the sensitivity of copepods to fluid mechanical signals generated by $M$. norvegica and that they initiated their escape reactions at distances $24 \%$ further away from the predators than in the dark. All things being equal, this should have resulted in a decreased feeding rate in the light. The fact that $M$. norvegica actually increased their feeding rate in the light (Torgersen 2001), suggests that vision plays an important role in their foraging.

\section{Mechanoreception}

Although light levels affected feeding rate, $M$. norvegica also detected and attacked prey in complete darkness. These detections and attacks must be caused by signals perceived through sensors other than vision; most likely mechanoreception. Onsrud and Kaartvedt (1998) reported that $M$. norvegica feed on copepods at depth and during the night. Their results are consistent with our observations that vision is not the sole sensory modality underlying prey detection by $M$. norvegica. Although mechanoreceptors are distributed throughout the body of $M$. norvegica, those on the anntenules are the most likely to be involved in prey detection (Patria and Wiese 2004). This is supported by our observations that the antennules move in the direction of prey as soon as they are detected. For many zooplankton predators, prey motion increases feeding rate (e.g. Cowles and Strickler 1983; Tiselius and Jonsson 1990) by increasing both the encounter rate and their conspicuousness to mechanosensitive predators (Fields and Yen 1993, 2002; Tiselius et al. 1997). Mechanoreception-triggered by the hydrodynamic disturbance of a swimming prey-is based upon the bending velocity of the mechanoreceptor located on the predator's antennae (Yen and Fields 1992; Kiorboe et al. 1999). The degree of the deformation of water corresponds to the size of the prey, its speed and the distance from the predator (Kiorboe et al. 1999). Thus, krill possess the sensory organs that underlie the perception of active prey at a distance, and independent of light, and our observations support their ability to do so. 
Avoidance and escape responses of copepods

The second possibility driving the higher feeding rates of $M$. norvegica in the light is that light alters the escape behaviour of their prey. In this study, we measured the escape threshold of Calanus spp. and the subsequent speed and escape distance in dark and light conditions. The distance at which the copepod initiated its escape response increased significantly in the light vs. the dark. This suggests that the behavioural threshold eliciting the escape reaction decreases with light. Thus, Calanus spp. may become more sensitive to fluid mechanical signals as their predation risk to visual predators increases. Furthermore, we found that light had no effect on either the escape speed or the distance travelled during the escape response. As discussed above, greater behavioural sensitivity and no measurable change in the escape speed should have decreased the predation risk of Calanus spp. in the light. However, to the contrary, the greater attack distances (this study) and the higher feeding rates of $M$. norvegica (Torgersen 2001) suggest that the increased visual acuity supersedes the ability of copepods to avoid predation. This may help to explain the strong selective pressure driving diel vertical migration in Calanus spp.

\section{Ecological relevance}

Understanding the relationship between predator detection and prey escape reactions are fundamental to predicting the number and species of prey that are consumed. In this study we have mapped the prey detection volume of Meganyctiphanes norvegica when preying on Calanus spp. These results can be incorporated into ecosystem models used to predict the importance of krill as a predator of copepods.

Acknowledgments We thank the crew of the RV Brattstrøm, T. Knutsen, L. Calise and A. Gundersen for assistance at sea, and R. Bjelland for practical help during the experiments. We are also grateful to W. Melle and S. Kaartvedt for improving the text through comments and constructive criticism. This research was supported by the Norwegian Institute of Marine Research (Sensory Biology and Behaviour Project) and the Research Council of Norway.

Open Access This article is distributed under the terms of the Creative Commons Attribution Noncommercial License which permits any noncommercial use, distribution, and reproduction in any medium, provided the original author(s) and source are credited.

\section{References}

Båmstedt U, Karlson K (1998) Euphausiid predation on copepods in coastal waters of the Northeast Atlantic. Mar Ecol Prog Ser 172:149-168
Brewer MC, Coughlin JN (1995) Virtual plankton: a novel approach to the investigation of aquatic predator-prey interactions. Mar Freshw Behav 26:91-100

Brodie PF, Sameoto DD, Sheldon RW (1978) Population densities of euphausiids off Nova Scotia as indicated by net samples, whale stomach contents, and sonar. Limnol Oceanongr 23:1264-1267

Browman HI, St-Pierre J-F, Skiftesvik AB, Racca R (2003) Behavior of Atlantic cod (Gadus morhua) larvae: an attempt to link maternal condition with larval quality. In: Browman HI, Skiftesvik $\mathrm{AB}$ (eds) The big fish bang. Institute of Marine Research, Bergen, pp 71-95

Catton KB, Webster DR, Brown J, Yen J (2007) Quantitative analysis of tethered and free-swimming copepodid flow fields. J Exper Biol 210:299-310

Cowles TJ, Strickler JR (1983) Characterization of feeding activity patterns in the planktonic copepod Centropages typicus Kroyer under various food conditions. Limnol Oceanogr 28:106-115

Denys CJ, Brown PK (1982) The rhodopsins of Euphausia superba and Meganyctiphanes norvegica (Crustacea, Euphausiacea). J Gen Physiol 80:451-472

Fields DM, Yen J (1993) Outer limits and inner structure: the 3dimensional flow field of Pleuromamma xiphias (Calanoida: Metridinidae). Bull Mar Sci 53:84-95

Fields DM, Yen J (2002) Fluid mechanosensory stimulation of behavior from a planktonic marine copepod, Euchaeta rimana Bradford. J Plankt Res 24:747-755

Fiksen $\varnothing$, Eliassen S, Titelman J (2005) Multiple predators in the pelagic: modeling behavioural cascades. J Anim Ecol 74:423429

Gophen M, Harris RP (1981) Visual predation by a marine cyclopoid copepod, Corycaeus anglicus. J Mar Biol Assoc UK 61:391-399

Hallberg E, Nilsson DE (1983) The Euphausiid compound eye-a morphological reinvestigation (Crustacea, Euphausiacea). Zoomorphology 103:59-66

Kaartvedt S, Larsen T, Hjelmseth K, Onsrud MSR (2002) Is the omnivorous krill Meganyctiphanes norvegica primarily a selectively feeding carnivore? Mar Ecol Prog Ser 228:193-204

Kaartvedt S, Rostad A, Fiksen O, Melle W, Torgersen T, Breien MT, Klevjer TA (2005) Piscivorous fish patrol krill swarms. Mar Ecol Prog Ser 299:1-5

Kiorboe T, Saiz E, Visser A (1999) Hydrodynamic signal perception in the copepod Acartia tonsa. Mar Ecol Prog Ser 179:97-111

Lass S, Tarling GA, Virtue P, Matthews JBL, Mayzaud P, Buchholz F (2001) On the food of northern krill Meganyctiphanes Norvegica in relation to its vertical distribution. Mar Ecol Prog Ser 214:177-200

McClatchie S (1985) Feeding behavior in Meganyctiphanes norvegica (M Sars) (Crustacea, Euphausiacea). J Exper Mar Biol Ecol $86: 271-284$

Montevecchi WA, Birtfriesen VL, Cairns DK (1992) Reproductive energetics and prey harvest of leachs storm-petrels in the northwest Atlantic. Ecol 73:823-832

Mori M, Butterworth DS (2006) A first step towards modelling the krill-predator dynamics of the Antarctic ecosystem. CCAMLR Sci 13:217-277

North EW, Gallego A, Petitgas P (eds) (2009) Manual of recommended practices for modelling physical-biological interactions during fish early life. ICES Coop Res Rep 295

Onsrud MSR, Kaartvedt S (1998) Diel vertical migration of the krill Meganyctiphanes norvegica in relation to physical environment, food and predators. Mar Ecol Prog Ser 171:209-219

Onsrud MSR, Kaartvedt S, Rostad A, Klevjer TA (2004) Vertical distribution and feeding patterns in fish foraging on the krill Meganyctiphanes norvegica. ICES J Mar Sci 61:1278-1290

Patria MP, Wiese K (2004) Swimming in formation in krill (Euphausiacea), a hypothesis: dynamics of the flow field, 
properties of antennular sensor systems and sensory-motor link. J Plankt Res 26:1315-1325

Ramcharan CW, Sprules WG (1986) Visual predation in MysisRelicta Loven. Limnol Oceanogr 31:414-420

Sameoto D, Neilson J, Waldron D (1994) Zooplankton prey selection by juvenile fish in Nova Scotian shelf basins. J Plankt Res 16:1003-1019

Stevick PT, Incze LS, Kraus SD, Rosen S, Wolff N, Baukus A (2008) Trophic relationships and oceanography on and around a small offshore bank. Mar Ecol Prog Ser 363:15-28

Tiselius P, Jonsson PR (1990) Foraging behavior of 6 Calanoid copepods-observations and hydrodynamic analysis. Mar Ecol Prog Ser 66:23-33

Tiselius P, Jonsson P, Kaartvedt S, Olsen E, Joerstad T (1997) Effects of copepod foraging behavior on predation risk: an experimental study of the predatory copepod Pareuchaeta norvegica feeding on Acartia clausi and A. tonsa (Copepoda). Limnol Oceanogr 42:164-170

Torgersen T (2001) Visual predation by the euphausiid Meganyctiphanes norvegica. Mar Ecol Prog Ser 209:295-299

Virtue P, Mayzaud P, Albessard E, Nichols P (2000) Use of fatty acids as dietary indicators in northern krill, Meganyctiphanes norvegica, from northeastern Atlantic, Kattegat, and Mediterranean waters. Can J Fisher Aquat Sci 57:104-114

Yen J, Fields DM (1992) Escape responses of Acartia hudsonica (Copepoda) nauplii from the flow field of Temora longicornis (Copepoda). Archiv Hydrobiol Beih 36:123-134

Yen J, Brown J, Webster DR (2003) Analysis of the flow field of the krill, Euphausia pacifica. Mar Freshw Behav Physiol 36:307319 